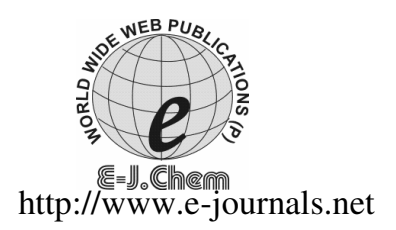

ISSN: 0973-4945; CODEN ECJHAO

E-Journal of Chemistry

2011, 8(4), 1632-1637

\title{
Zeolite (ZSM-5) as a Highly Efficient and Heterogeneous Catalyst for the Synthesis of $\beta$-Enaminones and $\beta$-Enamino Esters
}

\author{
AMIYA SHEKHAR and DEVENDRA DEO PATHAK* \\ Department of Applied Chemistry \\ Indian School of Mines, Dhanbad-826004, Jharkhand, India \\ ddpathak@yahoo.com
}

Received 28 December 2010; Accepted 28 February 2011

\begin{abstract}
Several $\beta$-enaminones and $\beta$-enaminoesters have been synthesized in high yields from amine and $\beta$-diketone in the presence of Zeolite (ZSM-5) as a catalyst. This method is applicable to both cyclic and acyclic ketones with aromatic and aliphatic amines.
\end{abstract}

Keywords: $\beta$-Enaminones, $\beta$-Enamino Esters, ZSM-5

\section{Introduction}

$\beta$-enaminones and $\beta$-enamino esters have been used as synthons for the synthesis of a variety of bioactive heterocycles ${ }^{1-3}$ and pharmaceuticals displaying anti-inflammatory ${ }^{4}$ antitumor ${ }^{5}$, antibacterial $^{6}$, anti-epileptic ${ }^{7-8}$, anti-convulsant ${ }^{9}$ and other therapeutic properties ${ }^{10,11}$. These compounds also serve as key intermediates in organic synthesis ${ }^{12-14}$ and their chemistry has undergone a renaissance of interest ${ }^{15}$. The most common and widely employed protocol involves direct condensation of $\beta$-dicarbonyl compounds with amines in aromatic hydrocarbon solvents under reflux with azeotropical removal of water ${ }^{16}$. Subsequently the reaction procedure has been modified with the use of several catalysts such a molecular iodine ${ }^{17}, \quad \mathrm{Bi}(\mathrm{TFA})_{3}{ }^{18}, \mathrm{NaAuClO}_{4}{ }^{19}, \mathrm{ZrOCl}_{2} \cdot 8 \mathrm{H}_{2} \mathrm{O}^{20}$, ionic liquid $\left[\mathrm{EtNH}_{3}\right] \mathrm{NO}_{3}{ }^{21}$, $\mathrm{HClO}_{4} \cdot \mathrm{SiO}_{2}{ }^{22}$, silica chloride ${ }^{23}$, ceric(IV)ammonium nitrate ${ }^{24}$. $\mathrm{Sc}(\mathrm{OTf})_{3}{ }^{25}$ and $\mathrm{Yb}(\mathrm{OTf})_{3}{ }^{26}$. Some other routes to the synthesis of $\beta$-Enaminones include condensation of methyl ketones with dimethylformamide dimethylacetals ${ }^{27}$, aminolysis of dithioacetals mediated by copper acetate $^{28}$, reductive cleavage of isoxazoles ${ }^{29}$, cyclization of aminoacids ${ }^{30}$ and substitution of the imidoylbenzotriazoles with trimethylsilyl enol ethers ${ }^{31}$. Out of these methods, most of them suffer from various disadvantages such as long reaction time and unspecified yields, use of expensive reagents, tedious work-up and lack of general applicability etc. The reaction has recently been reported to be catalysed by heterogeneous catalysts such as silica sulfuric acid ${ }^{32}$ and silica-supported $\mathrm{LiHSO}_{4}{ }^{33}$. 
Keeping in view the importance of these compounds, it is desirable to find out more efficient, environmental friendly, cheap and readily available catalysts for synthesis of $\beta$-enaminones and $\beta$-enamino esters. During the last few years, there has been a spurt in the use of inorganic solid acids, particularly zeolites, in organic reactions ${ }^{34-36}$ owing to their varied lewis and bronsted acidity, thermal stability, low cost and ease of separation. Prompted by these reports, we herein report a zeolite (ZSM-5) catalysed synthesis of various $\beta$-enaminones and $\beta$-enamino esters (Scheme 1).

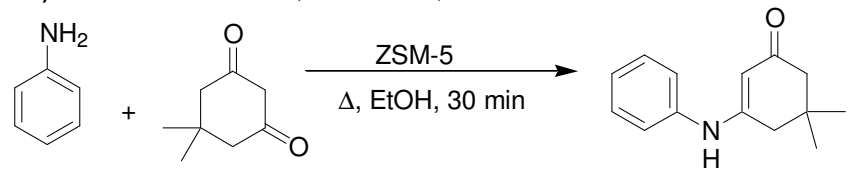

\section{Experimental}

\section{Scheme 1}

All the isolated compounds were characterized by IR, ${ }^{1} \mathrm{H}$ NMR, mass spectroscopy and melting point. The IR spectra were recorded in the range of 4000-400 $\mathrm{cm}^{-1}$ FT-IR spectrophotometer using $\mathrm{KBr}$ disk. Melting points were taken in open capillary tubes and therefore uncorrected. Purity of the compounds was checked on silica gel alumina sheet using n-hexane and ethylacetate as eluent. The visualization of spot was carried out in UV chamber. The ${ }^{1} \mathrm{H}$ NMR were recorded on Brucker $400 \mathrm{MHz}$ spectrometer in $\mathrm{CDCl}_{3}$ using TMS as an internal standard. The catalyst ZSM-5 (SAR-100) was purchased from ranbaxy (India) and used as received.

General procedure for the synthesis of $\beta$-enaminones and $\beta$-enamino esters derivatives

A mixture of amine $(1 \mathrm{mmol}), \beta$-carbonyl compound $(1 \mathrm{mmol})$ and zeolite $(0.04 \mathrm{~g})$ was placed in a $25 \mathrm{~mL}$ two-necked round-bottomed flask fitted with a reflux condenser. Ethanol $(2 \mathrm{~mL})$ was added to the mixture and the contents were heated under reflux till the completion of the reaction as monitored by TLC. After completion, the reaction was cooled to room temperature, solvent removed under reduced pressure and the crude product isolated with EtOAc $(2 \times 10 \mathrm{~mL})$. The combined portions were filtered, dried under vacuum. The crude product was recrystallised from EtOH/ $\mathrm{H}_{2} \mathrm{O}$.

\section{Spectral data of the product}

\section{5,5-Dimethyl-3-(phenylamino)cyclohex-2-enone ( Table 3, entry 1)}

Pale yellow solid; IR( KBr): 3236, 2958, 1720, 1573, 1244, $708 \mathrm{~cm}^{-1} ;{ }^{1} \mathrm{H}$ NMR $\left(\mathrm{CDCl}_{3}, 400\right.$ MHz): $\delta 1.12(\mathrm{~s}, 6 \mathrm{H}, 2 \mathrm{x} \mathrm{CH}), 2.23\left(\mathrm{~s}, 2 \mathrm{H}, 2 \mathrm{x} \mathrm{CH}_{2}\right), 2.34\left(\mathrm{~s}, 2 \mathrm{H}, \mathrm{CH}_{2}\right), 5.59(\mathrm{~s}, 1 \mathrm{H},=\mathrm{CH})$, 6.01 (br., $1 \mathrm{H},-\mathrm{NH}), 7.15-7.18(\mathrm{~m}, 3 \mathrm{H}, \mathrm{ArH}), 7.32-7.36(\mathrm{~m}, 2 \mathrm{H}, \mathrm{ArH})$; LCMS: Calculated data for $\mathrm{C}_{14} \mathrm{H}_{17} \mathrm{NO}: \mathrm{m} / z\left[\mathrm{M}^{+} \mathrm{H}\right]^{+}$216.299. Found 216.278.

The spectral data of rest of the products were matching to the literature value.

\section{Results and Discussion}

First of all, in order to screen the catalytic activity of the catalyst, i.e., ZSM-5, the reaction of aniline $(1 \mathrm{mmol})$ with dimedone $(1 \mathrm{mmol})$ was selected. Various reactions in the presence of different amount of catalyst in ethanol at room temperature and under reflux were carried out in order to optimize the reaction conditions (Table 1). It is clear from the Table 1 that the best results (maximum yields and minimum time) were obtained with $0.04 \mathrm{~g}$ of the catalyst in EtOH under reflux. 
Table 1. Effect of catalyst loading and temperature on the reaction of aniline with dimedone

\begin{tabular}{cccc}
\hline Amount of Zeolite, $\mathrm{g}$ & Temperature, ${ }^{\circ} \mathrm{C}$ & Time, min & Yield ${ }^{\mathrm{a}}, \%$ \\
\hline 0.01 & 25 & 120 & 5 \\
0.02 & 25 & 120 & 8 \\
0.04 & 25 & 120 & 14 \\
0.04 & 60 & 110 & 40 \\
0.04 & 70 & 100 & 55 \\
0.01 & 80 & 90 & 50 \\
0.02 & 80 & 65 & 62 \\
0.03 & 80 & 45 & 75 \\
0.04 & 80 & 30 & 93 \\
0.05 & 80 & 25 & 93 \\
\hline \multicolumn{4}{c}{}
\end{tabular}

After optimization of the catalyst concentration and temperature, the reaction was performed in various other solvents (Table 2) in order to study solvents effects. The best results were obtained using EtOH $(2 \mathrm{~mL})$ under reflux, though the reaction had also taken place in other solvents but with poor yields (Table 2).

Table 2. Study of solvent effects on the reaction of dimedone with aniline in the presence of ZSM-5

\begin{tabular}{cccc}
\hline Solvent & Temperature condition & Time, min & \% Yield $^{\mathrm{a}}$ \\
\hline $\mathrm{THF}$ & Reflux & 60 & 39 \\
$\mathrm{CH}_{3} \mathrm{CN}$ & Reflux & 60 & 48 \\
$\mathrm{CHCl}_{3}$ & Reflux & 60 & 53 \\
$\mathrm{MeOH}$ & Reflux & 60 & 61 \\
$\mathrm{EtOH}, 2 \mathrm{~mL}$ & Reflux & 60 & 93 \\
$\mathrm{EtOH}, 5 \mathrm{~mL}$ & Reflux & 60 & 85 \\
$\mathrm{EtOH}, 10 \mathrm{~mL}$ & Reflux & 60 & 80 \\
\hline
\end{tabular}

${ }^{a}$ Isolated yields

The products, after work up and recrystallization, were isolated either as off-white solids (Entry 1-8, Table 3) or as viscous liquids (Entry 9 and 10, Table 3). The products obtained were characterized by ${ }^{1} \mathrm{H}$ NMR and Mass spectrum, and comparing the data with the literature values. The ${ }^{1} \mathrm{H}$ NMR spectrum obtained on the product 5,5-dimethyl-3(phenylamino)cyclohex-2-enone (Table 3, entry 1) is shown in Figure 1.

Table 3. Synthesis of $\beta$-enaminones and $\beta$-enamino esters using ZSM-5 as a catalyst

Entry




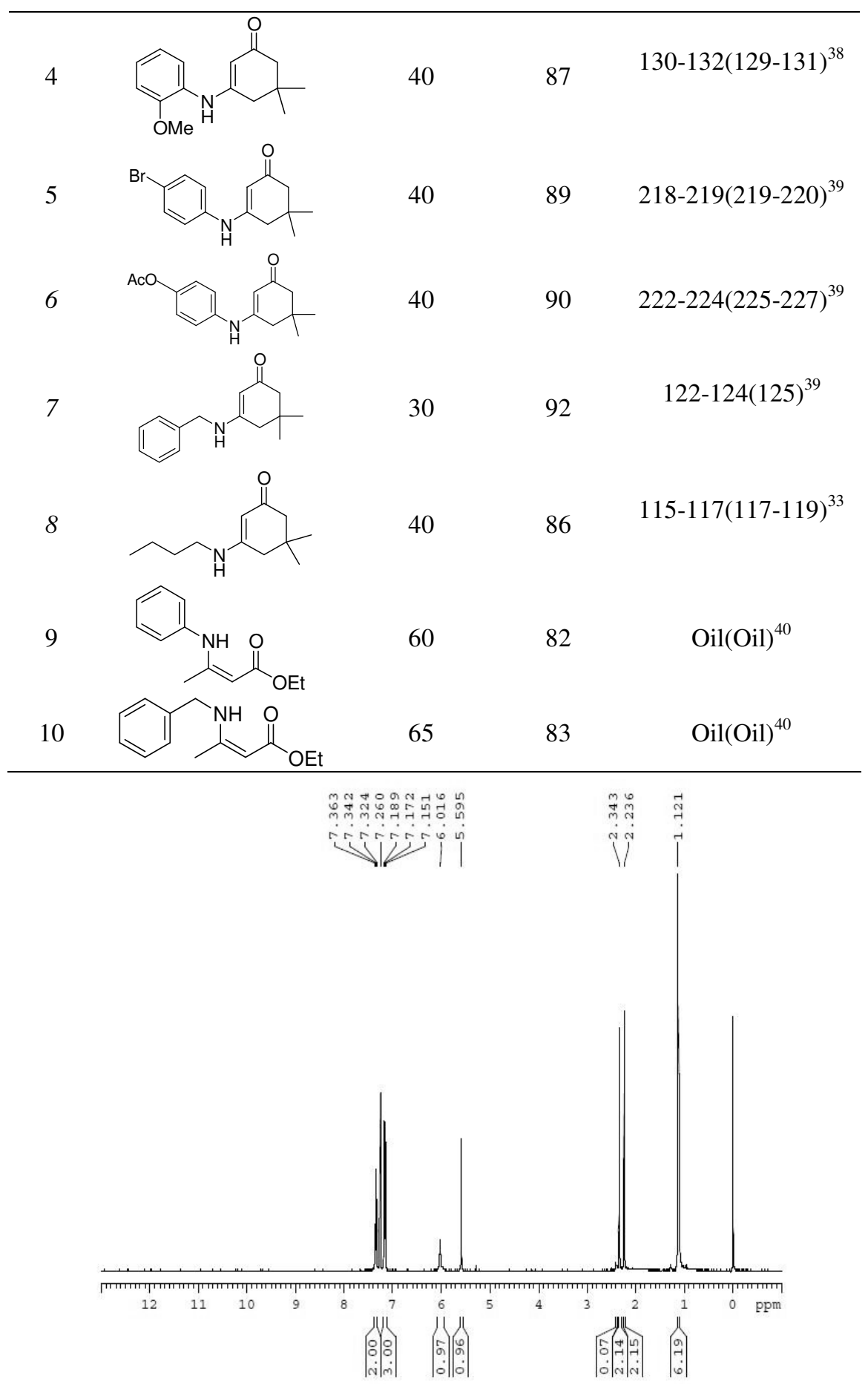

Figure 1. The ${ }^{1} \mathrm{H}$ NMR spectra of 5,5-dimethyl-3-(phenylamino)cyclohex-2-enone 
The methyl protons $\left(2 \times \mathrm{CH}_{3}\right)$ were observed at $\delta 1.12$, methylene protons $\left(2 \times \mathrm{CH}_{2}\right)$ at $\delta 2.33$ and 2.34 as singlets. The sharp singlets at $\delta 5.59$ and 6.01 were assigned to olefinic $(=\mathrm{CH})$ proton and $(-\mathrm{N} H)$ proton, respectively. The aromatic protons were obtained as a complex multiplet ranging from $\delta 7.12$ to 7.36 . The rest of the products were characterized by comparing the data with the literature values. It has been observed that the presence of electron withdrawing groups leads to slightly decreased yields and prolonged reaction time.

In summary, we have demonstrated that zeolite (ZSM-5) is an efficient, easily available and environmental friendly, heterogeneous catalyst for the synthesis of a number of $\beta$-enaminones and $\beta$-enamino esters. The catalyst works well with both aromatic and aliphatic amines and the corresponding cyclic or acyclic ketones to afford the desired product in good to excellent yields.

\section{Acknowledgment}

One of the Author (AS) would like to thank the Director of Indian School of Mines, Dhanbad for the award of ISM Junior Research Fellowship and Head, Department of Applied Chemistry for providing research facilities.

\section{References}

1 Alan C, Spivey A C, Srikaran R, Diaper C M, David J and Turner D, Org Biomol Chem., 2003, 1, 1638 and the references cited therein.

2 Michael J P, De Koning C B, Gravestock D, Hosken G D Howard A S, Jungmann C M, Krause R W M, Parsons A S, Pelly S C and Stanbury T V, Pure Appl Chem., 1999, 71, 979-988.

3 Hassneen H M and Abdallah T A, Molecules, 2003, 8, 333-341.

4 Michael J P, De Koning C B, Gravestock D, Hosken G D, Howard A S, Jungmann C M, Krause R W M, Parsons A S, Pelly S C and Stanbury T V, Pure Appl Chem., 1999, 71, 979-988.

5 Boger D L, Ishizaki T, Jr Wysocki J R J, Munk S A, Kitos P A and Suntornwat O, J Am Chem Soc., 1989, 111, 6461.

6 Wang Y F, Izawa T, Kobayashi S and Ohno M, J Am Chem Soc., 1982, 104, 6465-6466.

7 Edafiogho I O, Ananthalakshmi K V V and Kombian S B, Bioorg Med Chem., 2006, 14, 5266-5272.

8 Khurana M, Salama N N, Scott K R, Nemieboka N N, Jr Bauer K S and Eddington N D, Biopharm Drug Dispos., 2003, 24(9), 397-407.

9 Edafiogho I O, Alexander M S, Moore J A, Farrar V A and Scott K R, Curr Med Chem., 1994, 1, 159-175.

10 White J D and Ihle D C, Org Lett., 2006, 8, 1081.

11 Edafiogho I O, Kombian S B, Ananthalakshmi K Y V V, Salama N N, Eddington N D, Wilson T L, Alexander M S, Jackson P L, Hanson C D and Scott K R, J Pharm Sci., 2007, 96, 2509.

12 Rappoport Z, (Eds.), The Chemistry of Enamines John Wiley \& Sons, New York, 1994, Part 1, pp 525-639.

13 Vohra R K, Renaud J L and Bruneau C, Collect Czech Chem Commun., 2005, 70, 1943.

14 Stevens C V, Kesteleyn B, Alonso E R and De Kimpe N, Tetrahedron, 2001, 57, 7685.

15 Elassar A Z A and El-Khair A A, Tetrahedron, 2003, 59, 8463-8480.

16 Martin D F, Janusonis G A and Martin B B, J Am Chem Soc., 1961, 83, 73.

17 Gogoi S, Bhuyan R and Barua N C, Synth Commun., 2005, 35, 2811.

18 Khosropur A R, Khodaei M M and Kookhazadeh M, Tetrahedron Lett., 2004, 45, 1725. 
19 Arcadi A, Bianchi G, Giuseppe S D and Marinelli F, Green Chem., 2003, 5, 64-67.

20 Zhang Z H, Li T-S and Li J J, Catal Commun., 2007, 8, 1615.

21 Bhosale R S, Suryawanshi P A, Ingle S A, Lokhande M N, More S P, Mane S B, Bhosale S V and Pawar R P, Synlet., 2006, 933.

22 Das B, Venkateswarlu K, Majhi A, Reddy M R, Reddy K N, Rao Y K, Ravikumar K and Srihar B, J Mol Catal A: Chem., 2006, 246, 276.

23 Gholap A R, Chakor N S, Daniel T, Lahoti R J and Srinivasan K V, J Mol Catal A: Chem., 2006, 245, 37.

24 Paira M, Misra R and Roy S C, Ind J Chem., 2008, 47B, 966-969.

25 Yadav J S, Kumar V N, Rao R S, Priyadarshini A D, Rao P P, Reddy B V S and Nagaiah K, J Mol Catal A: Chem., 2006, 256, 234.

26 Epifano F, Genovese S and Curini M, Tetrahedron Lett., 2007, 48, 2717-2720.

27 Martins M A P, Frizzo C P, Moreira D N, Rosa F A, Marzari M R B, Zanata N and Bonacorso H G, Catal Commun., 2007, 9(6), 1375.

28 Kang J, Liang F, Sun S G, Liu Q and Bi X H, Org Lett., 2006, 8, 2547-2550.

29 Calle M, Calvo L A, Gonzales-Ortega A and Gonzales-Nogal A, Tetrahedron, 2006, 62, 611.

30 Turunen B J and Georg G I, J Am Chem Soc., 2006, 128, 8702-8703.

31 Katritzky A R, Hayden A E, Kirichenko K, Pelpheri P M and Ji Y, J Org Chem., 2004, 69, 5108.

32 Hasaninejad A, Zare A, Mohammadizadeh M R and Shekouhy M, J Iran Chem Soc., 2010, 7(1), 69-76.

33 Hasaninejad A, Zare A, Mohammadizadeh M R, Shekouhy M and Moosavi-Zare A R E- J Chem., 2010, 7(4), 1546-1554.

34 Salehi P, Dabiri M, Zolfigol M A and Fard M A B, Heterocycles, 2003, 60, 2435-2440.

35 Lin H, Ding J, Chen X and Zhang Z, Molecules, 2000, 5, 1240-1243.

36 Mobinikhaledi A, Foroughifar N and Karimi G, Synth React Inorg Metal-Org NanoMetal Chem., 2007, 37, 279-282.

37 Scott K R, Edafiogho I O, Richardson E L, Farrar V A, Moore J A, Tietz E I, Hinko C N, Chang H, El-Assadi A and Nicholson J M, J Med Chem., 1993, 36, 1947-1955.

38 Iida H, Yuasa Y and Kibayashi C, J Org Chem., 1980, 45, 2938.

39 Mohammadizadeh M R, Hasaninejad A, Bahramzadeh M and Khanjarloo Z S, Synth Commun., 2009, 39, 1152.

40 Zhang Z H, Yin L and Wang Y M, Adv Synth Catal., 2006, 348, 184 


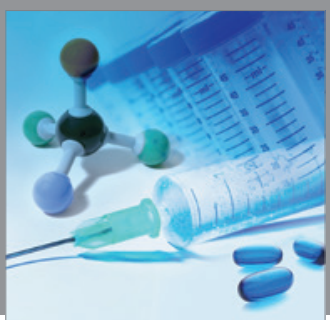

International Journal of

Medicinal Chemistry

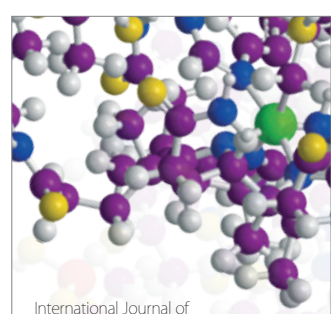

Carbohydrate Chemistry

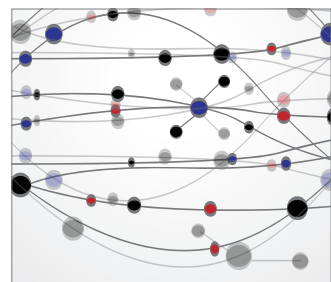

The Scientific World Journal
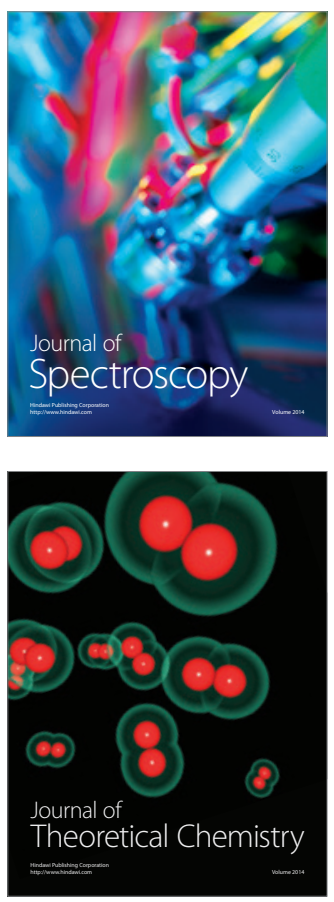
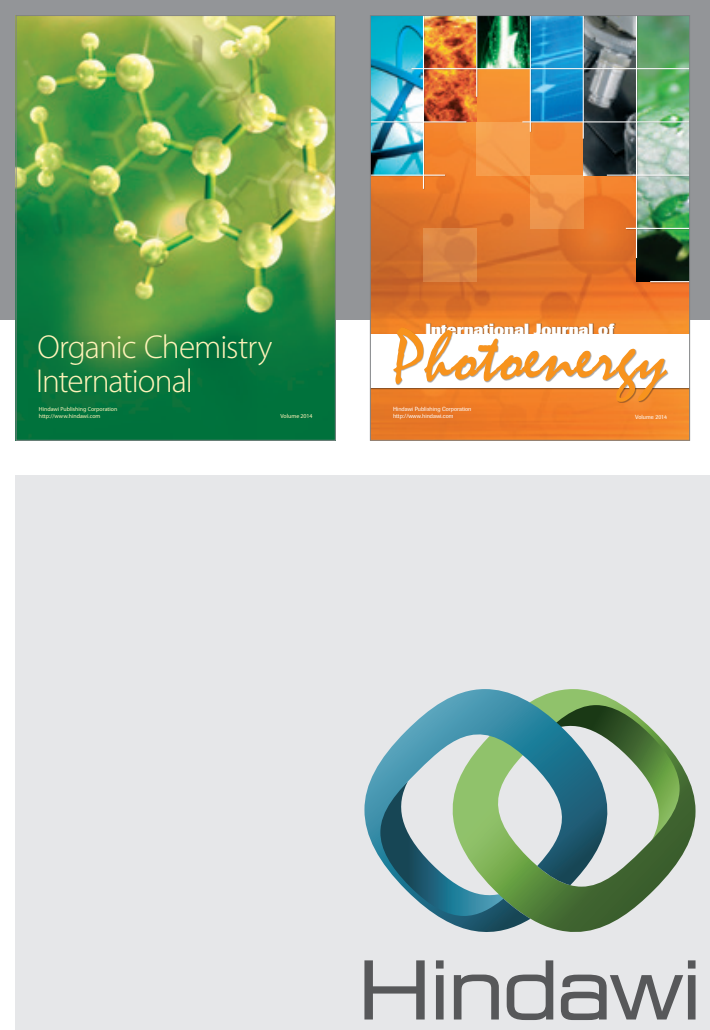

Submit your manuscripts at

http://www.hindawi.com
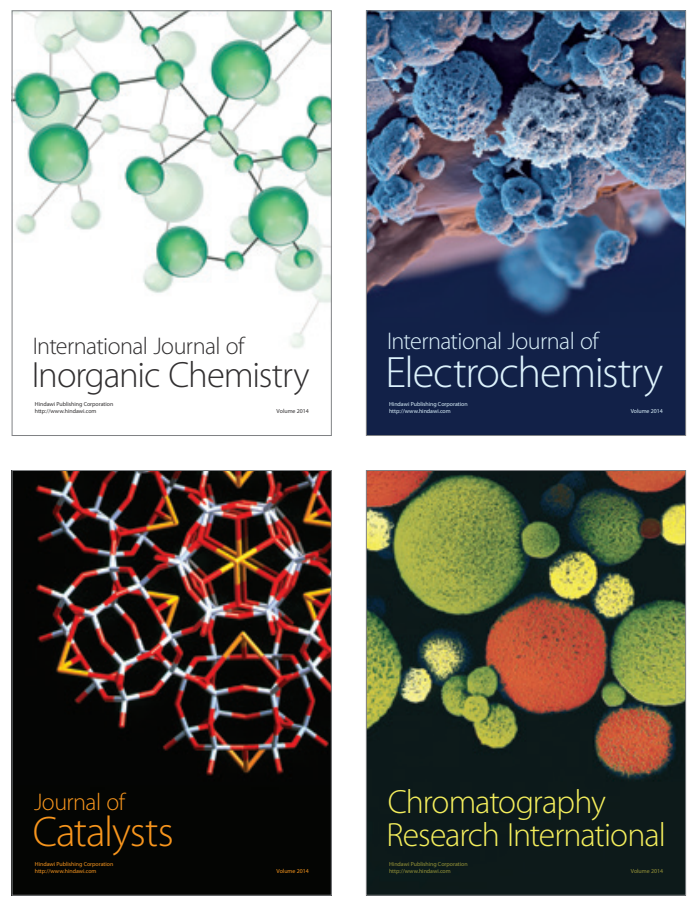
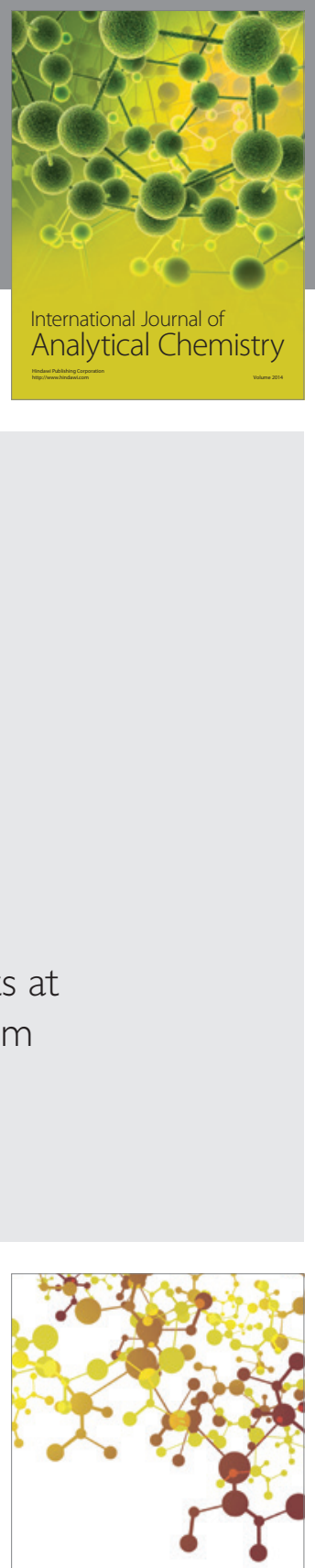

Journal of

Applied Chemistry
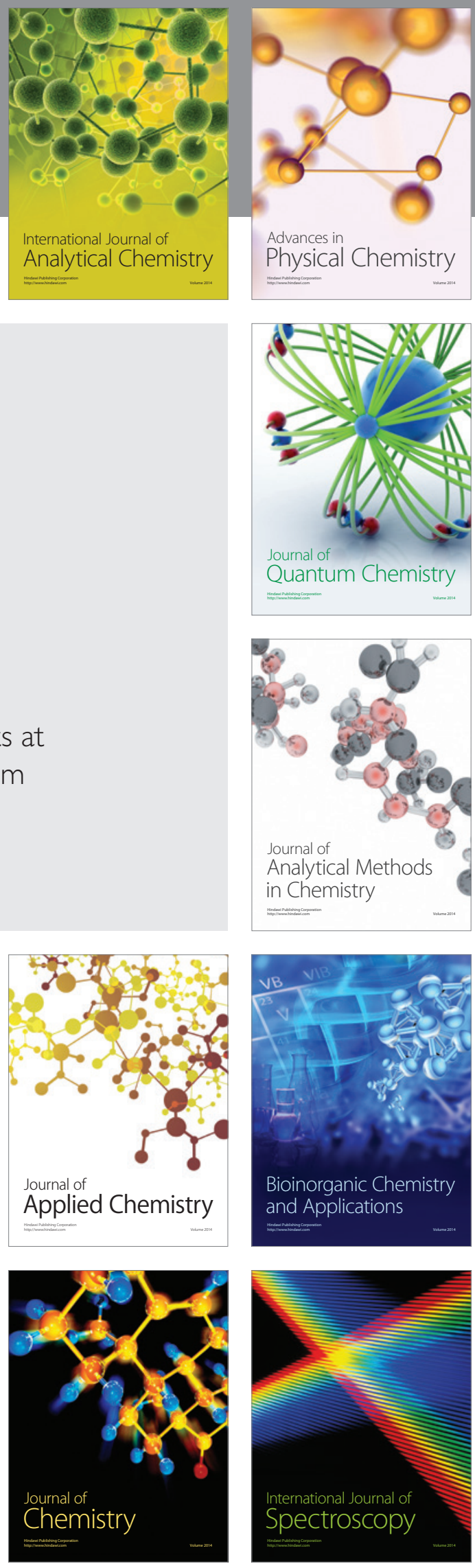